\title{
Natural Variation in Neuron Number in Mice Is Linked to a Major Quantitative Trait Locus on Chr 11
}

\author{
Robert W. Williams, Richelle C. Strom, and Dan Goldowitz \\ Center for Neuroscience, Department of Anatomy and Neurobiology, University of Tennessee, \\ Memphis, Tennessee 38163
}

\begin{abstract}
Common genetic polymorphisms-as opposed to rare mutations-generate almost all heritable differences in the size and structure of the CNS. Surprisingly, these normal variants have not previously been mapped or cloned in any vertebrate species. In a recent paper (Williams et al., 1996a), we suggested that much of the variation in retinal ganglion cell number in mice, and the striking bimodality of strain averages, are caused by one or two quantitative trait loci (QTLs). To test this idea, and to map genes linked to this variable and highly heritable quantitative trait, we have counted ganglion cells in 38 recombinant inbred strains (BXD and $B X H$ ) derived from parental strains that have high and low cell numbers. A genome-wide search using simple and composite interval-mapping techniques revealed a major QTL on chromosome (Chr) 11 in a $3 \mathrm{cM}$ interval between Hoxb and Krt1 (LOD = 6.8; genome-wide $p=0.001$ ) and possible subsidiary QTLs on Chr 2 and Chr 8. The Chr 11 locus,
\end{abstract}

neuron number control 1 (Nnc1), accounts for one third of the genetic variance among $\mathrm{BXH}$ strains and more than half of that among BXD strains, but Nnc1 has no known effects on brain weight, eye weight, or total retinal cell number. Three strong candidate genes have been mapped previously to the same region as Nnc1. These genes-Rara, Thra, and Erbb2- encode receptors for retinoic acid, thyroxine, and neuregulin, respectively. Each receptor is expressed in the retina during development, and their ligands affect the proliferation or survival of retinal cells.

Key words: brain evolution; brain weight; composite interval mapping; gene polymorphism; inner nuclear layer; linkage analysis; mouse chromosome 11; natural variation; neuron number; optic nerve; outer nuclear layer; quantitative trait locus; recombinant inbred strains; regression analysis; retinal ganglion cell
The most conspicuous differences between the brains of different mammalian species are quantitative (Haug, 1987; Williams and Herrup, 1988). Total brain weight, size of different brain nuclei, and numbers of neurons can vary over two or three orders of magnitude (Finlay and Darlington, 1995). This marked variation ultimately traces back to differences that are generated, selected, and propagated within single species. Two impressive examples of variation in the human CNS include the threefold difference in the density of cone photoreceptors in the fovea (Curcio et al., 1987) and the threefold differences in the total area of both primary and secondary visual cortex (Gilissen and Zilles, 1996). Some of this variation is undoubtedly environmental, but most appears to be generated by the independent segregation of genes that control the proliferation and survival of neurons and glial cells. None of these naturally polymorphic genes have yet been mapped or identified in any vertebrate. These genes are particularly important because they ultimately influence the behavioral repertoire of species.

Received Sept. 3, 1997; revised Oct. 20, 1997; accepted Oct. 21, 1997.

This research was supported by National Eye Institute Grants EY08868 and EY09586 (R.W., D.G.), National Institute of Neurological Disorders and Stroke Grant R01 NS35485 (R.W.), and United States Public Health Service Training Grant GRNS-07323 (R.C.S.). Institutional and mouse colony support was provided by the Center for Neuroscience at the University of Tennessee. We thank K. Manly for his program Map Manager QT; and Drs. J. Cheverud, R. Elliott, K. Manly, D. Rice, B. Taylor, D. Wahlsten, G. Zhou, and the anonymous reviewers for comments and advice. We also thank K. Graehl for editorial help and K. Troughton and R. Cushing for technical help.

Internet access: Information on individual cases is available at URL http://mickey.utmem.edu/neuron.html.

Correspondence should be addressed to Dr. Robert W. Williams, Department of Anatomy and Neurobiology, 855 Monroe Avenue, Memphis, TN 38163.

Copyright (C) 1997 Society for Neuroscience $0270-6474 / 97 / 180138-09 \$ 05.00 / 0$
Genetic variation in complex traits is thought to be generated by large numbers of loci that usually have comparatively small effects on phenotypes (Lande, 1981). However, a subset of these loci can have surprisingly large individual effects (Lai et al., 1994). For example, single quantitative trait loci (QTLs) have been shown to account for $20-40 \%$ of the variance in the height of corn and the weight of tomatoes (Tanksley, 1993). Similarly, several QTLs individually account for as much as $10-20 \%$ of the total variance in numbers of sensory bristles in fruit flies. Some of these QTLs are now known to correspond to key proneural and neurogenic genes, including achaete-scute, atonal, enhancer of split, hairy, Notch, and scabrous (Mackay, 1995).

To map genes that contribute to normal variation in the vertebrate CNS, we focused on a single, well defined class of sensory neurons called retinal ganglion cells. Axons of these neurons give rise to the optic nerve and are essential for transmitting visual information from the eye to the thalamus and midbrain. We have shown recently that variation in ganglion cell number in mice is generated primarily by genetic factors $\left(h^{2} \sim 0.8\right)$ (Williams et al., 1996a). The distribution of ganglion cell number is close to normal, with a mean of 60,000 and a range from 32,000 to 87,000 . In this respect, variation in ganglion cell number is a typical complex trait displaying continuous variation over a wide range. However, one surprising finding from this previous work is that the distribution of inbred strain averages-as opposed to individual values - is distinctly bimodal, with modes near 55,500 and 63,500 (Williams et al., 1996a). This pattern could be generated by the segregation of high and low alleles at a major QTL. In this study, we have pursued this possibility and have mapped a QTL to 


\begin{tabular}{|c|c|c|c|c|}
\hline Strain & $\begin{array}{l}\text { Mean } \pm \text { SEM }^{*} \\
(1000 \times)\end{array}$ & Type $^{a}$ & Brain $^{b}(\mathrm{mg})$ & $\begin{array}{l}\text { Residuals } \\
(\text { cells } 1000 \times)\end{array}$ \\
\hline C57BL/6J & $55.4 \pm 0.8$ & $\mathrm{~L}$ & 475 & \\
\hline $\mathrm{DBA} / 2 \mathrm{~J}$ & $63.4 \pm 1.2$ & $\mathrm{H}$ & 412 & \\
\hline BXD1 & $60.3 \pm 1.1$ & I & 465 & -4.67 \\
\hline BXD2 & $65.9 \pm 1.8$ & $\mathrm{H}$ & 432 & 3.88 \\
\hline BXD5 & $75.5 \pm 1.3$ & $\mathrm{H}$ & 526 & 5.09 \\
\hline BXD6 & $62.7 \pm 0.9$ & $\mathrm{H}$ & 388 & 4.60 \\
\hline BXD8 & $62.8 \pm 2.1$ & $\mathrm{H}$ & 412 & 2.56 \\
\hline BXD9 & $65.6 \pm 1.7$ & $\mathrm{H}$ & 422 & 4.47 \\
\hline BXD11 & $61.0 \pm 1.1$ & I & 437 & -1.47 \\
\hline BXD12 & $56.8 \pm 2.1$ & $\mathrm{~L}$ & 434 & -5.40 \\
\hline BXD13 & $54.7 \pm 1.7$ & $\mathrm{~L}$ & 427 & -6.88 \\
\hline BXD14 & $64.0 \pm 1.6$ & $\mathrm{H}$ & 442 & 1.08 \\
\hline BXD15 & $63.8 \pm 1.1$ & $\mathrm{H}$ & 443 & 0.79 \\
\hline BXD16 & $64.0 \pm 1.3$ & $\mathrm{H}$ & 469 & -1.33 \\
\hline BXD18 & $55.1 \pm 0.9$ & $\mathrm{~L}$ & 427 & -6.48 \\
\hline BXD19 & $67.1 \pm 1.3$ & $\mathrm{H}$ & 431 & 5.16 \\
\hline BXD20 & $59.9 \pm 1.9$ & I & 398 & 0.91 \\
\hline BXD21 & $60.0 \pm 1.5$ & I & 443 & -3.00 \\
\hline BXD22 & $64.5 \pm 1.1$ & $\mathrm{H}$ & 457 & 0.25 \\
\hline BXD23 & $53.0 \pm 1.0$ & $\mathrm{~L}$ & 434 & -9.20 \\
\hline BXD24 & $62.4 \pm 1.0$ & $\mathrm{H}$ & 391 & 4.03 \\
\hline BXD25 & $53.8 \pm 1.5$ & $\mathrm{~L}$ & 431 & -8.14 \\
\hline BXD27 & $50.8 \pm 1.1$ & $\mathrm{~L}$ & 393 & -7.75 \\
\hline BXD28 & $52.4 \pm 1.9$ & $\mathrm{~L}$ & 407 & -7.40 \\
\hline BXD29 & $63.6 \pm 1.4$ & $\mathrm{H}$ & 413 & 3.27 \\
\hline BXD30 & $66.0 \pm 1.3$ & $\mathrm{H}$ & 399 & 6.92 \\
\hline BXD31 & $66.6 \pm 1.2$ & $\mathrm{H}$ & 426 & 5.11 \\
\hline BXD32 & $75.8 \pm 2.2$ & $\mathrm{H}$ & 434 & 13.60 \\
\hline
\end{tabular}

${ }^{*}$ SEM values are corrected for bias attributable to small sample size. The average number of BXD animals studied per strain was 7 (range, 5-11).

${ }^{a} \mathrm{H}$ indicates high type; L, low type; I, intermediate type.

${ }^{b}$ Brain weights were corrected by regression analysis for differences in sex, body weight, and age (Fig. $3 A$ ). Values given are normalized to those of 75 -d-old $22 \mathrm{gm}$ females. SEM values are all $<10 \mathrm{mg}$.

a gene-rich region on chromosome (Chr) 11 between Hoxb and Krt1 using recombinant inbred (RI) strains.

\section{MATERIALS AND METHODS}

RI strains. We used $26 \mathrm{BXD}$ and $12 \mathrm{BXH}$ RI strains to map genes responsible for variation in retinal ganglion cell number. All strains were obtained from The Jackson Laboratory (Bar Harbor, ME). RI strains are generated by crossing fully inbred strains and then continuously inbreeding successive generations (Bailey, 1981; Taylor, 1989; Plomin et al., 1991; Belknap et al., 1992). During the first 10-15 generations, before inbreeding is complete, chromosomal segments inherited from the two parental strains recombine several times during successive meioses. However, by the 20th generation of inbreeding, the recombinant chromosomes are almost completely homozygous. The unique patterns of recombination in each RI strain are preserved by continued inbreeding.

The BXD strains were generated by crossing C57BL/6J females to DBA/2J males. The BXH strains were generated by crossing C57BL/6J females to $\mathrm{C} 3 \mathrm{H} / \mathrm{HeJ}$ males (Taylor, 1978). We chose these RI sets because neuron numbers differ significantly between the parental pairs (Williams et al., 1996a); C57BL/6J belongs to the group of strains that has a low cell population, whereas DBA/ $2 \mathrm{~J}$ and $\mathrm{C} 3 \mathrm{H} / \mathrm{HeJ}$ belong to the group that has a high cell population. The $\mathrm{C} 3 \mathrm{H} / \mathrm{HeJ}$ parental strain and eight of its descendant $\mathrm{BXH}$ strains (BXH2, 3, 4, 7, 8, 9, 14, and 16) are homozygous for the photoreceptor degeneration allele $r d$ at the $\beta$-phosphodiesterase locus on Chr 5. Despite a massive loss of photoreceptors during the first 2 months of life, this mutation has no detectable effect on the retinal ganglion cell population (Williams et al., 1996a).

\begin{tabular}{|c|c|c|c|c|}
\hline Strain & $\begin{array}{l}\text { Mean } \pm \text { SEM } \\
(1000 \times)\end{array}$ & Type & Brain (mg) & $\begin{array}{l}\text { Residuals } \\
(\text { cells } 1000 \times)\end{array}$ \\
\hline C57BL/6J & $55.4 \pm 0.8$ & $\mathrm{~L}$ & 475 & \\
\hline $\mathrm{C} 3 \mathrm{H} /{ }^{b}$ & $67.0 \pm 1.7$ & $\mathrm{H}$ & 427 & \\
\hline $\mathrm{BXH} 2$ & $64.6 \pm 2.2$ & $\mathrm{H}$ & 431 & 2.48 \\
\hline BXH3 & $63.0 \pm 2.1$ & I & 442 & 2.20 \\
\hline BXH4 & $66.9 \pm 3.3$ & $\mathrm{H}$ & 465 & 8.86 \\
\hline BXH6 & $52.3 \pm 1.4$ & $\mathrm{~L}$ & 455 & -6.94 \\
\hline BXH7 & $56.5 \pm 2.2$ & I & 471 & -0.82 \\
\hline BXH8 & $62.4 \pm 2.2$ & I & 437 & 1.00 \\
\hline ВXH9 & $57.5 \pm 1.8$ & I & 457 & -1.50 \\
\hline BXH10 & $56.2 \pm 1.0$ & I & 455 & -3.04 \\
\hline BXH11 & $55.0 \pm 1.7$ & $\mathrm{~L}$ & 431 & -7.12 \\
\hline BXH12 & $69.5 \pm 1.0$ & $\mathrm{H}$ & 432 & 7.50 \\
\hline BXH14 & $65.6 \pm 2.5$ & $\mathrm{H}$ & 432 & 3.60 \\
\hline BXH19 & $55.3 \pm 2.8$ & $\mathrm{~L}$ & 436 & -6.22 \\
\hline
\end{tabular}

${ }^{a}$ Conventions as in Table 1. Neuron numbers are based on an average of 5.5 cases per strain (range, 4-9); brain weights based on an average of 9.0 cases per strain (range, 3-13). Brain weights were normalized by regression for sex, weight, and age differences. All SEM values of brain weight are $<8 \mathrm{mg}$.

${ }^{b}$ Ganglion cell counts were pooled from three $\mathrm{C} 3 \mathrm{H} / \mathrm{HeJ}$ and three $\mathrm{C} 3 \mathrm{H} / \mathrm{HeSnJ}$ cases.

There is no significant difference in ganglion cell number between $\mathrm{BXH}$ strains with or without the mutant allele; wild-type strains average $58,300 \pm 4400 \mathrm{SE}(n=4)$, whereas the $r d / r d$ strains average 61,500 \pm $2000(n=8)$.

Mapping QTLs with RI strains. Mapping QTLs involves looking for an association between variation in phenotype and variation in alleles at loci that have already been mapped. In our case, the ordered array of cell number phenotypes among the set of RI strains, also called a strain distribution pattern, was compared with ordered arrays of genotypes at many hundreds of loci that have been typed in BXD and BXH strains.

Genome-wide linkage statistics. A concordance between phenotypes and genotypes at a particular locus may indicate the presence of a nearby QTL. However, given the large number of tests involved in a genomewide linkage analysis, even a tight association between phenotypes and genotypes may occur by chance (Lander and Schork, 1994; Lander and Kruglyak, 1995; Belknap et al., 1996). Therefore it is essential to estimate genome-wide probabilities of achieving particular linkage statistics by chance alone. We computed genome-wide error thresholds corresponding to $p=0.5,0.05$, and 0.001 using a robust nonparametric permutation method developed by Churchill and Doerge (1994) that is implemented by Map Manager QT. To do this, we compared the peak logarithm of the likelihood ratio (the LOD score) of the correctly ordered data (e.g., Table 1, column 2) with the peak LOD scores computed for 5000-10,000 random permutations of the same data. For example, if the real data gave a peak LOD score of 6 , and only 1 of 1000 random permutations exceeded this value, then the genome-wide probability of a false-positive would be $\sim 0.001$. The $p=0.5$ level, a level considered suggestive of a QTL, corresponds to an LOD score that is exceeded by the highest LOD scores of half of the permutations (Lander and Kruglyak, 1995).

Interval mapping. Mapping was carried out using the program Map Manager QT (ftp://mcbio.med.buffalo.edu/pub/MapMgr/QT/). This program uses computationally efficient regression equations developed by Haley and Knott (1992) and Tinker and Mather (1995) to map QTLs (K. Manly, MapManager QT manual, 1996). The probability of linkage between neuron number and genotypes was estimated at $1 \mathrm{cM}$ intervals along the entire genome, the Y chromosome excepted. Once principal QTLs were mapped, we used a composite interval mapping method to search for other QTLs with more modest effects on neuron number. Composite interval mapping (Jansen, 1993; Zeng, 1993, 1994; Tinker and Mather, 1996) is a refinement that absorbs effects associated with known or suspected QTLs during an analysis of other QTLs. Files used for mapping are available at http://mickey.utmem.edu/neuron.html. Mapping data have been deposited with the Mouse Genome Database (The Jackson Laboratory). 
The RI genotype database. The original $\mathrm{BXD}$ and $\mathrm{BXH}$ mapping data files, compiled by R. W. Elliott and B. Taylor, were downloaded from the Roswell Park Cancer Institute (Buffalo, NY; ftp://mcbio.med. buffalo.edu/pub/MapMgr/data/). The files are comprehensive and include 1522 loci mapped on BXD strains and 500 loci mapped on the BXH strains. Many of these loci have identical strain-distribution patterns. All loci with redundant and incompletely typed strain-distribution patterns, and loci with numerous unexplained double recombinants over short intervals, were deleted from the datasets. The final BXD set used for mapping and permutation analysis contained 529 loci. The BXH file contained 271 loci. Both datasets define a mouse genome that is 1500 $1600 \mathrm{cM}$ in length. Given this high-density genetic map, it is not surprising that genes with large quantitative effects can be mapped using RI strains without genotyping additional marker loci.

Combining linkage data from independent datasets. Recombination events accumulate during the generation of RI strains, expanding the genetic map fourfold relative to a conventional linkage cross (Bailey, 1981) and substantially refining QTL map position. However, this advantage is offset by the low statistical power of typically small RI sets (Belknap et al., 1996). To increase the likelihood of detecting QTLs, we combined data from two RI sets. We computed the probability associated with a $\chi^{2}$ value equal to $-2\left(\ln P_{\mathrm{BXD}}+\ln P_{\mathrm{BXH}}\right)$ with $4 \mathrm{df}$, where $\ln P_{\mathrm{BXD}}$ and $\ln P_{\mathrm{BXH}}$ are the natural logarithms of the probabilities derived independently for the two RI sets in the same interval.

Fixation and processing of tissue. Eyes, optic nerves, and brains were taken from 182 BXD cases, 66 BXH cases, and 45 cases from the three parental strains. Mice of both sexes and a wide range of ages $(30-400$ d) were anesthetized with an injection of Avertin $(1.25 \%$ 2,2,2tribromoethanol and $0.8 \%$ tert-pentyl alcohol in water, $0.5-0.8 \mathrm{ml}$, i.p.) and were perfused transcardially with sodium PBS, followed by $1.25 \%$ glutaraldehyde and $1.0 \%$ paraformaldehyde in $0.1 \mathrm{M}$ phosphate buffer, and then by $2.5 \%$ glutaraldehyde and $2.0 \%$ paraformaldehyde. Nerves were dissected, osmicated, and embedded in Spurr's resin. Brains, including the olfactory bulbs, were dissected and weighed. Thin sections of one or both nerves were placed on Formvar-coated slot grids and stained with uranyl acetate and lead citrate. The nerves were examined and photographed on an electron microscope using a systematic sampling protocol described previously in detail (Williams et al., 1996a).

Estimating ganglion cell number. Retinal ganglion cell number was estimated by counting axons within the optic nerve. Ganglion cells are known to contribute only one axon to the optic nerves in virtually all vertebrates. Neither bifurcation nor rare centripetal axons are likely to alter significantly the $1: 1$ ratio of ganglion cells and optic axons in any strain of mouse (for review, see Rice et al., 1995a; Williams et al., 1996a). A counting frame was traced on negatives with a marker, and all axons within the frame and intersecting the upper and right edges were marked and counted on the negatives. To ensure that unmyelinated fibers were detected, negatives were counted while wearing magnifying glasses. The effective magnification was $>25,000 \times$. Approximately 90 cases were replicated independently. All data were entered into a spreadsheet program (Excel 5, Microsoft). The average density of axons was multiplied by the area of the nerve cross-section to estimate the total axon population. Strain averages are presented as unweighted means.

Regression analysis. Regression analysis was performed to minimize nonselective effects of variation in brain and body weight on retinal ganglion cell numbers. We used the program DataDesk 6 (Data Description, Ithaca, NY) to perform linear regression and to compute cell number residuals after eliminating variance associated with differences in sex, age, and body and brain weight. Average brain weight for each strain was adjusted to that expected of sets of 75-d-old $22 \mathrm{gm}$ females (Williams et al., 1997). This improved the uniformity of comparisons across strains. A regression analysis of the strain averages of brain weight and neuron number was then performed to compute the residuals listed in Tables 1 and 2.

Analysis of retinas. A 1-mm-wide strip of retina and pigment epithelium, extending from the head of the optic nerve to the inferior ora, was cut from one eye from each of 16 cases and embedded flat in Spurr's resin. The $1-\mu \mathrm{m}$-thick sections were cut along the radial axis, mounted, and stained with hematoxylin. Slides were coded. Complete central to peripheral cross-sections of the ventral retina were drawn at low power. The radial depth of cells in the inner and outer nuclear layers was determined at 7-11 evenly spaced sites along all sections at $400 \times$ magnification using differential interference contrast optics. Ambiguity of these counts at single sites is less than \pm 2 cells. The outer nuclear layer
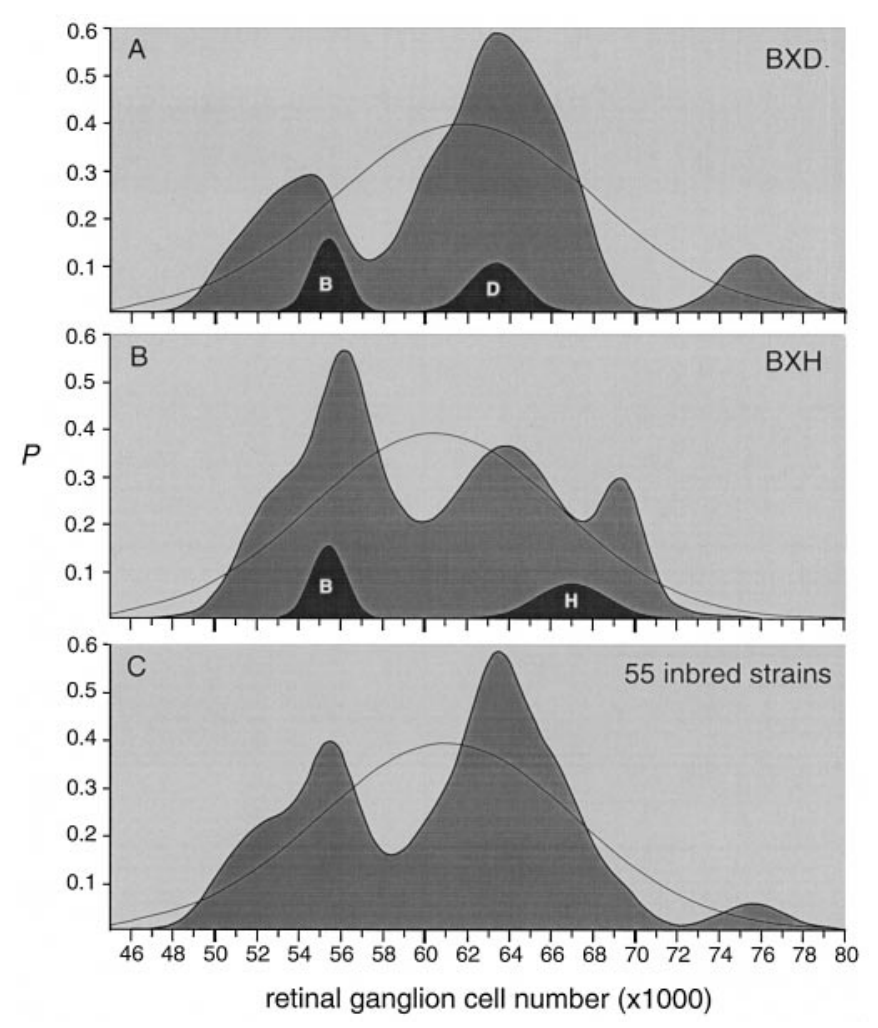

Figure 1. A, Probability density of strain averages for the BXD RI strains (bold curve) suggests that there are three relatively distinct phenotypes. The small functions labeled $B$ and $D$ are Gaussian probability density functions of the parental strains. A set of 26 similar functions for BXD strains was added to generate the summed probability density for the entire BXD series. The expected Gaussian function is drawn in lightly. $B$, Probability density function for the $12 \mathrm{BXH}$ strains (bold curve) and the two parental strains. $C$, A summed probability density function for all 55 inbred strains of mice, including the 38 RI strains listed in this paper and 17 standard inbred strains listed by Williams et al. (1996a). This large collection is less subject to sampling error and provides our best estimate of the effect of allelic substitutions at Nnc1. $F_{1}$ hybrids between high and low strains typically have intermediate cell populations between 56,000 and 64,000 (average, 61,500; $n=7$ ) (Williams et al., 1996a).

is between 5 and 15 cells deep, whereas the inner layer is between 2 and 6 cells deep. The average coefficient of variation within a case for these measurements was $5.8 \%$ in the outer layer and $7.5 \%$ in the inner layer.

\section{RESULTS}

\section{Variation among RI strains}

The average ganglion cell population in the BXD strains extends from a low of $50,800 \pm 1100$ in BXD27 to a high of 75,800 \pm 2000 in BXD32 (Table 1). The probability density function for the 26 BXD strains has modes at 54,500 and 63,500 (Fig. 1A). These modes correspond almost precisely to the means of the parental strains and are aligned with the modes discovered in our previous analysis of 17 standard inbred strains (Williams et al., 1996a, their Fig. 4). Four strains-BXD1, BXD11, BXD20, and BXD21have averages that are in the central range $(59,900$ to 61,000$)$, reasonably close to the midparental value of 59,000. Strains BXD5 and BXD32, both of which have very high cell numbers, represent a third mode. Average cell number in the set of $\mathrm{BXH}$ strains extends from 51,000 to 70,000 without significant transgression above or below the parental values (Table 2). The probability density function for these strains is broad and character- 


\begin{tabular}{|c|c|c|c|c|c|c|c|c|c|c|c|c|c|c|c|c|c|c|c|c|c|c|c|c|c|c|c|}
\hline \multirow[t]{2}{*}{ Locus } & \multirow[t]{2}{*}{$\mathrm{cM}^{a}$} & \multicolumn{6}{|c|}{ BXD Strain } & \multirow{2}{*}{$\begin{array}{l}1 \\
1\end{array}$} & \multirow{2}{*}{$\begin{array}{l}1 \\
2\end{array}$} & \multirow{2}{*}{$\begin{array}{l}1 \\
3\end{array}$} & \multirow{2}{*}{$\begin{array}{l}1 \\
4\end{array}$} & \multirow{2}{*}{$\begin{array}{l}1 \\
5\end{array}$} & \multirow{2}{*}{$\begin{array}{l}1 \\
6\end{array}$} & \multirow{2}{*}{$\begin{array}{l}1 \\
8\end{array}$} & \multirow{2}{*}{$\begin{array}{l}1 \\
9\end{array}$} & \multirow{2}{*}{$\begin{array}{l}2 \\
0\end{array}$} & \multirow{2}{*}{$\begin{array}{l}2 \\
1\end{array}$} & \multirow{2}{*}{$\begin{array}{l}2 \\
2\end{array}$} & \multirow{2}{*}{$\begin{array}{l}2 \\
3\end{array}$} & \multirow{2}{*}{$\begin{array}{l}2 \\
4\end{array}$} & \multirow{2}{*}{$\begin{array}{l}2 \\
5\end{array}$} & \multirow{2}{*}{$\begin{array}{l}2 \\
7\end{array}$} & \multirow{2}{*}{$\begin{array}{l}2 \\
8\end{array}$} & \multirow{2}{*}{$\begin{array}{l}2 \\
9\end{array}$} & \multirow{2}{*}{$\begin{array}{l}3 \\
0\end{array}$} & \multirow{2}{*}{$\begin{array}{l}3 \\
1\end{array}$} & \multirow{2}{*}{$\begin{array}{l}3 \\
2\end{array}$} \\
\hline & & 1 & 2 & 5 & 6 & 8 & 9 & & & & & & & & & & & & & & & & & & & & \\
\hline RGC number & & $\mathrm{U}$ & $\mathrm{H}$ & $\mathrm{H}$ & $\mathrm{H}$ & $\mathrm{H}$ & $\mathrm{H}$ & $\mathrm{U}$ & $\mathrm{L}$ & $\mathrm{L}$ & $\mathrm{H}$ & $\mathrm{H}$ & $\mathrm{H}$ & $\mathrm{L}$ & $\mathrm{H}$ & $\mathrm{U}$ & $\mathrm{U}$ & $\mathrm{H}$ & $\mathrm{L}$ & $\mathrm{H}$ & $\mathrm{L}$ & $\mathrm{L}$ & $\mathrm{L}$ & $\mathrm{H}$ & $\mathrm{H}$ & $\mathrm{H}$ & $\mathrm{H}$ \\
\hline D11Ncvs58 & 56 & $\mathrm{~B}$ & $\mathrm{D}$ & $\mathrm{D}$ & $\mathrm{B}$ & $\mathrm{D}$ & $\mathrm{D}$ & B & $\mathrm{D}$ & B & $\mathrm{D}$ & $\mathrm{D}$ & $\mathrm{D}$ & B & $\mathrm{D}$ & $\mathrm{D}$ & $\mathrm{D}$ & $\mathrm{D}$ & B & B & B & $\mathrm{D}$ & B & $\mathrm{D}$ & B & $\mathrm{B}$ & $\mathrm{D}$ \\
\hline Hoxb & 56 & $\mathrm{~B}$ & $\mathrm{D}$ & $\mathrm{D}$ & $\overline{\mathrm{D}}$ & $\mathrm{D}$ & $\mathrm{D}$ & $\mathrm{B}$ & $\overline{\mathrm{B}}$ & B & $\mathrm{D}$ & $\mathrm{D}$ & $\mathrm{D}$ & $\mathrm{B}$ & $\mathrm{D}$ & $\mathrm{D}$ & $\mathrm{D}$ & $\mathrm{D}$ & B & $\overline{\mathrm{D}}$ & B & $\overline{\mathrm{D}}$ & $\mathrm{B}$ & $\mathrm{D}$ & $\overline{\mathrm{D}}$ & $\overline{\mathrm{B}}$ & $\mathrm{D}$ \\
\hline Tstap $91 A$ & 57 & $\mathrm{~B}$ & $\mathrm{D}$ & $\mathrm{D}$ & $\mathrm{D}$ & $\mathrm{D}$ & $\mathrm{D}$ & B & $\mathrm{B}$ & B & $\mathrm{D}$ & $\mathrm{D}$ & $\mathrm{D}$ & B & $\mathrm{D}$ & $\mathrm{D}$ & $\mathrm{D}$ & $\mathrm{D}$ & B & $\mathrm{D}$ & B & $\overline{\mathrm{B}}$ & B & $\mathrm{D}$ & $\mathrm{D}$ & $\bar{B}$ & $\mathrm{D}$ \\
\hline Krt1 & 58 & B & $\mathrm{D}$ & $\mathrm{D}$ & $\mathrm{D}$ & $\mathrm{D}$ & $\mathrm{D}$ & B & B & B & $\mathrm{D}$ & $\mathrm{D}$ & $\mathrm{D}$ & B & $\mathrm{D}$ & $\mathrm{D}$ & $\mathrm{D}$ & $\mathrm{D}$ & B & $\mathrm{D}$ & B & B & B & B & $\mathrm{D}$ & $\bar{B}$ & $\mathrm{D}$ \\
\hline Mpmv8 & 62 & B & $\mathrm{D}$ & $\mathrm{D}$ & $\mathrm{D}$ & $\mathrm{D}$ & $\mathrm{D}$ & B & B & B & $\mathrm{D}$ & $\mathrm{D}$ & B & $\mathrm{D}$ & $\mathrm{D}$ & $\mathrm{D}$ & $\mathrm{D}$ & $\mathrm{D}$ & B & D & B & B & B & $\bar{B}$ & $\mathrm{D}$ & $\bar{B}$ & $\mathrm{D}$ \\
\hline
\end{tabular}

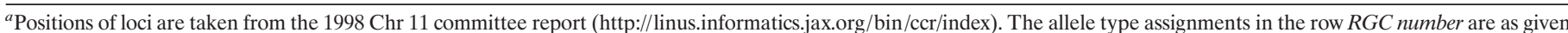

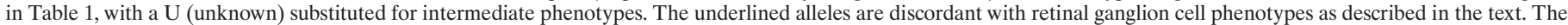
best match is with Tstap91A ( 1 discordant allele in strain BXD31; $r=0.69$ ). To compute correlations, $B$ alleles are coded as 0 , and $D$ alleles are coded as 1.

ized by a prominent peak at 56,000 and two less well resolved peaks at 64,000 and 69,500 (Fig. 1B.)

In fully homozygous RI lines, the independent assortment of $n$ diallelic loci gives rise to a maximum of $2^{n}$ genotypes (e.g., if $n=$ 2 then the genotypes are $a a b b, a a B B, A A b b$, and $A A B B)$, and each genotype is expected to be represented equally in the set of RI strains. If a large number of loci with intermediate or small additive effects on ganglion cell number assort independently during the generation of BXD and $\mathrm{BXH}$ strains, the probability densities in Figure 1 would tend to have a unimodal and perhaps Gaussian form. In contrast, the broad and multimodal distributions of the RI sets and the clearly bimodal distribution of all 55 inbred strains (Fig. 1C) suggest that a small number of QTLs have major effects on neuron number. This is consistent with our findings in $F_{2}$ intercrosses, in which the number of effective factors controlling ganglion cell number has been found to be less than three (Strom et al., 1996). A comparison of variance within and among RI strains indicates that genetic factors account for $\sim 70 \pm 10 \%$ of the total phenotypic variance (Hegmann and Possidente, 1981; Williams et al., 1996a).

\section{Mapping major effect QTLs}

\section{Linkage of absolute cell number phenotypes}

The distribution of phenotypes listed in Tables 1 and 2 can be compared directly with those loci that have already been mapped. The single best match on the densely mapped set of BXD strains is to the tissue-specific transplantation antigen $91 \mathrm{~A}$ gene (Tstap91A) located $\sim 2 \mathrm{cM}$ distal to Hoxb on Chr 11 (WatkinsChow et al., 1996). The correlation coefficient between neuron number and alleles at Tstap91A is +0.69 . (For the correlation analysis, $B$ alleles at Mendelian loci are arbitrarily assigned a value of 0 , and $D$ alleles are assigned a value of 1 ). The LOD score for linkage of absolute numbers of retinal ganglion cells with Tstap $91 \mathrm{~A}$ is 3.7. Table 3 illustrates the excellent concordance between strains with low and high cell numbers with alleles among the BXD strains at Tstap $91 A$ inherited respectively from $\mathrm{C} 57 \mathrm{BL} / 6 \mathrm{~J}$ and $\mathrm{DBA} / 2 \mathrm{~J}$ parental strains. The probability of achieving this concordance at any single locus (or in any $1 \mathrm{cM}$ interval between flanking markers) is 0.000037 for a test against a single marker and 0.06 for multiple tests covering the entire genome. These statistics apply to a two-way test in which phenotypes of the parental strains are not considered. The respective one-way analysis in which $B$ alleles inherited from the low parental strain $(\mathrm{C} 57 \mathrm{BL} / 6 \mathrm{~J})$ are associated with low phenotypes in the $\mathrm{BXD}$ strains gives corresponding point-wise and genome-wide probabilities of 0.000018 and 0.03 .

\section{Linkage after correcting for variation in brain and body weights}

Absolute differences in neuron number reflect both a component that is specific to ganglion cells and a component that is common to many, if not most, other CNS cell populations. This predictable global influence can be minimized by computing cell number residuals after regressing cell number against brain weight (Table 1, far right column; also see Fig. $3 A$ ). Brain weights themselves were corrected by regression to account for differences in sex, age, and body weight. Mapping these corrected numbers resulted in a significant improvement in the strength of linkage (LOD $=4.4$; single-point $p=0.000007$; genome-wide $p<0.05$; two-way test).

\section{Linkage analysis by composite interval mapping}

Two other chromosomal intervals-one on Chr 2, the other on Chr 8 -were shown to be well correlated with the remaining genetic variation in ganglion cell number (see below). By using composite interval mapping, we corrected for the effects of these two intervals and for that of a third interval on proximal Chr 11 near Glns-ps1, where we have mapped a major QTL that affects brain weight (Williams et al., 1996b; Gilissen and Williams, 1997). Using this method, linkage between variation in ganglion cell number and Tstap $91 A$ reaches a LOD of 6.8 (Fig. $2 ; p=2.0 \times$ $10^{-8}$, genome-wide $p<0.001$, two-way). We have named this QTL on Chr 11 Neuron number control 1 (Nnc1). Nnc1 maps between the Hoxb complex and $M p m v 8$, an interval of $\sim 3 \mathrm{cM}$ (Fig. 2). The probability of linkage drops $>100$-fold outside of this short interval. Independent support for this linkage assignment is provided by the $\mathrm{BXH}$ strain data, in which one of the strongest associations between $H$ alleles and strains with high cell population $\left(r=+0.58 ; r^{2}=0.34\right)$ is also on mid-distal Chr 11 between Scya3 and Krt1 (Fig. $3 B$ ) ( $p=0.01$; see below).

An analysis of the $12 \mathrm{BXH}$ strains shows that much of the variation in neuron number in this RI set could be accounted for by a QTL on Chr 4. The correlation between alleles at $S s d h 1$ on Chr 4 and cell number is tight but negative (Fig. $3 B)(r=-0.92$; LOD $=4.8$; genome-wide $p<0.05$ ). Despite these persuasive statistics, we suspect that this linkage is spurious. First, $B$ alleles inherited from the parental strain with low cell number are consistently associated with high cell number in BXH strains (Fig. 3B, boxed strain numbers). Such a reversal, although not uncommon in mapping QTLs that have modest effects, is highly unlikely for a QTL with such a large apparent effect $\left(r^{2}=0.8\right)$. Second, there is no support for this interval on the much larger set of BXD strains. Finally, the strain distribution pattern at Ssdh1 on Chr 4 is nearly opposite that of Scya3 on Chr 11 (Fig. $3 B$, circled strain numbers). Scya3 maps within $10 \mathrm{cM}$ of Tstap91a. 


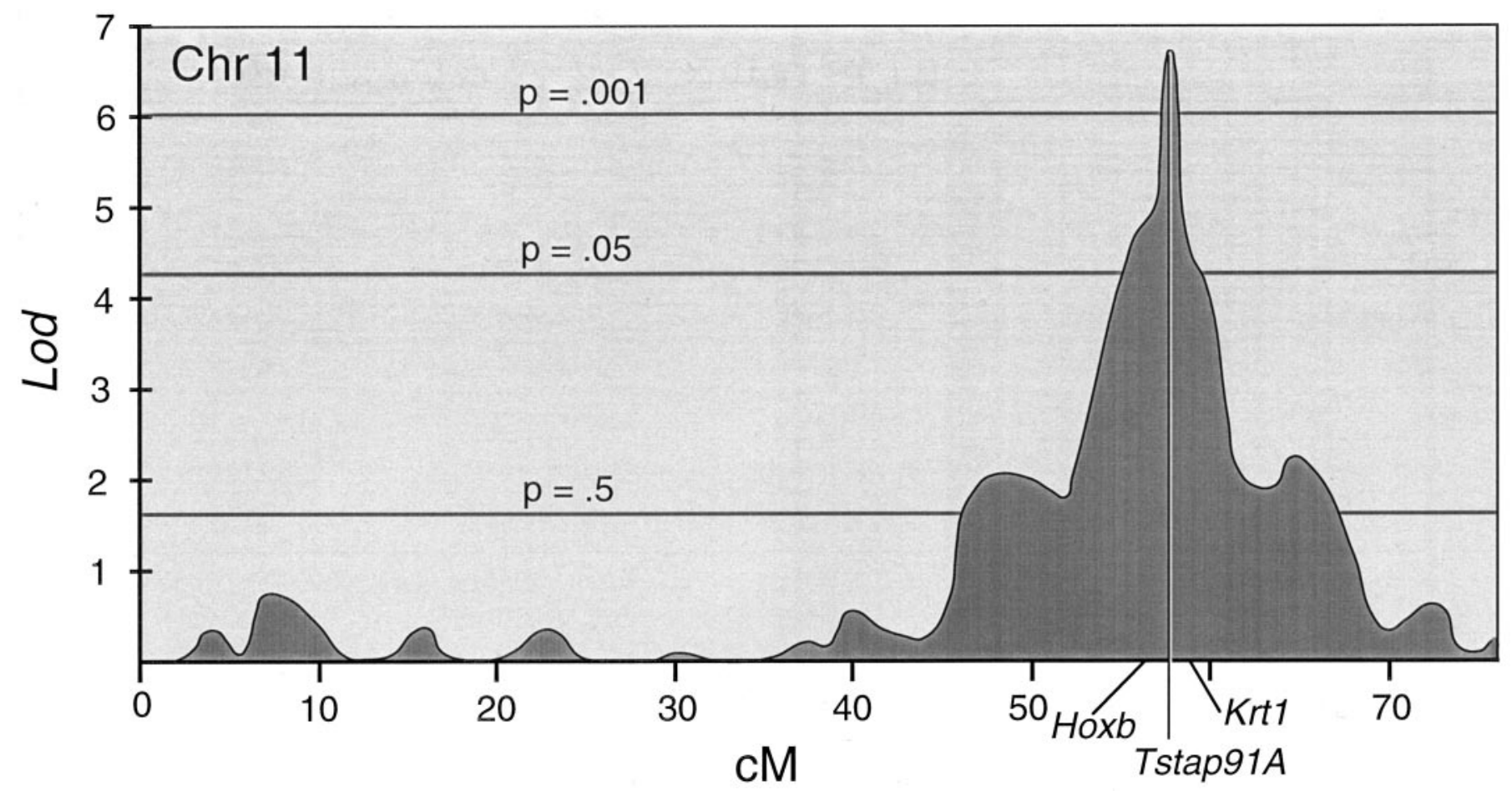

Figure 2. Linkage between variation in retinal ganglion cell number and genetic loci on Chr 11 . LOD scores were computed at $1 \mathrm{cM}$ intervals using a composite interval-mapping method that controls for variance associated with Hdc on Chr 2, D8Ncvs36 on Chr 8, and Glns-ps1 on proximal Chr 11. The horizontal lines mark the genome-wide significance levels computed by permutation analysis.

After controlling for variance associated with $\mathrm{Nnc1}$ on Chr 11, two additional intervals were highlighted in both RI sets that are associated with much of the remaining variance in neuron number. The first interval is located near L pl, D8Mit8, and D8Ncvs49 on Chr 8 (30-32 cM). The combined LOD for BXD and BXH RI sets in this interval is 3.0 (single-point $p=0.00020$; genome-wide $p=0.4)$. The second interval is near B2m, Hds, and Mltr10 on Chr $2(69-74 \mathrm{cM})$ and has a combined LOD of 2.4. (single-point $p=$ 0.001 ; genome-wide $p=0.6$ ). Clearly, the statistics are not strong enough to claim QTLs in either interval. However, these two intervals are near the $p=0.5$ criterion level considered suggestive of a QTL by Lander and Kruglyak (1995) (see Materials and Methods).

The phenotypic effects of alleles at single loci are difficult to estimate from sets of RI strains, and estimates tend to be too high (Lynch and Walsh, 1998). However, in the case of the neuron number phenotype, the clear separation between high and low modes, shown particularly well in Figure 1, provides a direct way to estimate effects of allele substitutions. Among BXD strains, the substitution of both $B$ alleles with $D$ alleles at $N n c 1$ is associated with an increase of $\sim 9000$ ganglion cells. The large size of this effect is consistent with the high correlation coefficient between cell counts and alleles at Tstap91A $\left(r=0.69\right.$ and $r^{2}=0.48$ for absolute counts; $r=0.74$ and $r^{2}=0.54$ for the residuals). Nnc1 generates at least $50 \%$, and perhaps as much as $70 \%$, of the total genetic variance in ganglion cell number among BXD mice. Based on the analysis of $F_{1}$ hybrids between high and low strains, the mode of gene action is primarily additive (Williams et al., 1996a). Collectively, as much as $70 \%$ of the heritable variation in neuron number, and as much as $50 \%$ of the total phenotypic variance among mice, can be accounted for by Nnc1 and by subsidiary QTLs that may map to Chr 2 and Chr 8 .

\section{Selectivity of action}

Variation in neuron number is often correlated positively with variation in brain weight (Fig. 3) (Zamenhof and van Marthens, 1978; Williams et al., 1993). The correlation between ganglion cell number and brain weight across the BXD and parental strains is +0.54 , a highly significant value $\left(r^{2}=0.29 ; F_{(1,24)}=10.0 ; p=\right.$ 0.004). However, alleles at marker loci close to Nncl do not correlate well with brain weight (Fig. $3 A ; r^{2}=0.13$ at Tstap91A). Furthermore, in the BXH set, the correlation between brain weight and neuron number is weakly negative (Fig. $3 B)(r=$ $-0.3)$. This indicates that QTLs controlling variation in retinal ganglion cell number do not have notable effects on brain weight and therefore do not have global effects on neuron number in the CNS. However, given the large number of distinct cell populations in the CNS, Nncl may well have pleiotropic effects on other CNS populations.

We have begun to assess the specificity of action of Nncl within the eye and retina. Variation in the size of the ganglion cell population does correlate positively with eye weight $(r=$ $0.55)$ and retinal area $(r=0.52)$ in BXD strains (Zhou and Williams, 1997). However, as is true for brain weight, there is no significant correlation between eye weight and alleles at loci on mid-distal Chr 11. The major QTLs controlling variation in eye weight among BXD strains map to proximal Chr 5 and midproximal Chr 15 (Zhou and Williams, 1997). To determine whether Nncl affects other cell populations in retina, we counted cells within the inner and outer plexiform layers of two parental strains (C57BL/6J and DBA/2J), three RI strains with low ganglion cell number (BXD13, BXD23, and BXD28), and three strains with high ganglion cell number (BXD9, BXD22, and BXD32). There are large differences between 
A

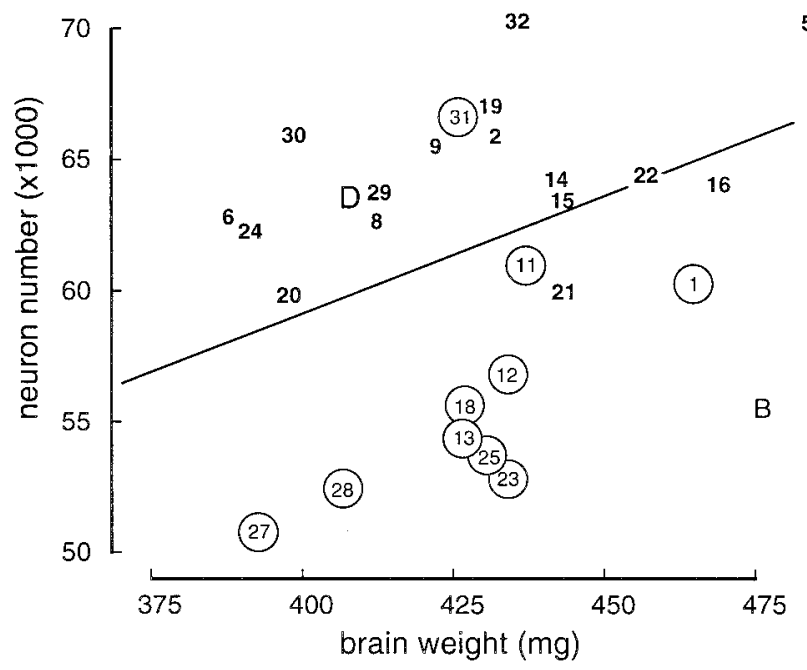

B

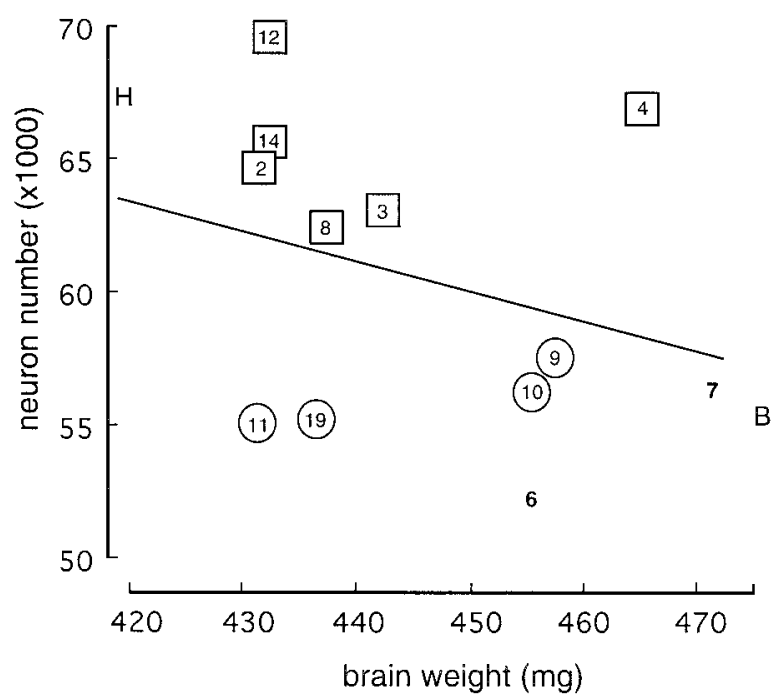

Figure 3. Regression analysis of brain weight on retinal ganglion cell number in RI strains. In both scattergrams, the numbers in scatterplots correspond to particular strains listed in Tables 1 and 2. $A$, Scattergram of the BXD strains. The $\mathrm{C} 57 \mathrm{BL} / 6 \mathrm{~J}$ parental strain is labeled $B$, and the DBA/2J parental strain is labeled $D$. The strains that are circled have the $B$-type allele at the Tstap91A locus on Chr 11. Only strain BXD31 is discordant, with a $B$ allele but a high cell population. Brain weights have been corrected for differences in sex, age, and body weight. The equation for the regression line is $y=23.5+0.09 x$, where $y$ equals neurons $(1000 \times)$ and $x$ equals brain weight in milligrams. $B$, Scattergram of the $\mathrm{BXH}$ strains. The $\mathrm{C} 3 \mathrm{H} / \mathrm{HeJ}$ parental strain is represented by the letter $H$. Strains that are circled have the $B$ allele at the Scya3 locus on Chr 11 . (Tstap91A has not been mapped on the BXH strains, but $S c y a 3$ is a locus known to map 5-10 cM proximal to Tstap91A.) Strains that are boxed have the $B$ allele at the $S s d h 1$ locus on $\mathrm{Chr} 4$. The equation for the regression line in B is $y=114-0.12 x$.

cases and strains (Fig. 4), from a low of $6.2 \pm 0.3$ cells per radial column in the photoreceptor layer in a BXD32 case with a ganglion cell population of 85,600 cells to a high of $11.5 \pm 0.5$ cells in a BXD28 case with a ganglion cell population of 43,600 . The correlation coefficient between ganglion cell number and the cell depth of the photoreceptor layer is -0.32 (95\% $\mathrm{CI}$ of $r$ is -0.71 to +0.21$)$. However, the correlation coefficient between numbers of ganglion cells and cells in the inner nuclear layer (amacrine, bipolar, horizontal, and Müller glial cells) is +0.53 (CI from +0.05 to +0.81 ). Collectively, these results suggest that $\mathrm{Nncl}$ is unlikely to have general positive effects on all cell populations in the retina, but the locus may have positive action on some cell classes in the inner nuclear layer. This is clearly an interesting and complex issue worth additional analysis.

\section{DISCUSSION}

\section{Synopsis}

We have mapped a gene locus that has a remarkably large effect on numbers of retinal ganglion cells in mice. Replacing both alleles from the low strain with alleles from the high strain boosts cell numbers by 9000 , a $15 \%$ increase. This large effect has allowed us to map the $\mathrm{Nnc1}$ locus to a $3 \mathrm{cM}$ interval on $\mathrm{Chr} 11$ between Hoxb and Krt1 using a modest number of RI strains.

\section{A comparison of methods used to map QTLs in the nervous system}

QTLs can be mapped using RI strains, as we have done in this study, or using groups of intercross and backcross progeny. One of the main advantages of RI strains is that nongenetic sources of variance can be reduced by repeatedly phenotyping the same recombinant genotype (Bailey, 1981; Dains et al., 1996). This is a key issue when phenotypes are sensitive to uncontrolled developmental and environmental factors or when measurement techniques are noisy. In this study, we typically counted the ganglion cell population of six or more mice of the same genotype and reduced nongenetic variance more than twofold. A second advantage of RI strains is that complementary genetic, developmental, pharmacological, and physiological studies can be performed by many investigators using the same recombinant strains. Finally, mapping QTLs with RI strains usually does not require additional genotyping. More than 1500 loci already have been mapped in BXD strains and, as we have shown, these data can be used to map QTLs with remarkable precision.

Several investigators (Plomin et al., 1991; Kanes et al., 1996; Buck et al., 1997) have suggested that RI strains be used primarily in a first-stage QTL analysis to highlight intervals that might be worth additional pursuit using backcross and intercross progeny. An alternative strategy that may prove as effective, particularly when QTLs have comparatively large effects (Belknap et al., 1996; Williams et al., 1998), is simply to increase the number of RI lines included in an analysis and to pool across independent RI sets. In our case, the first 12 BXD strains that we studied highlighted several candidate intervals, including mid-distal $\mathrm{Chr}$ 11. The addition of the remaining 14 BXD strains winnowed the initial list of candidates and greatly strengthened linkage with Tstap $91 A$. Adding the $12 \mathrm{BXH}$ recombinant strains and using composite interval mapping enabled us to detect secondary QTLs that we might otherwise have missed. Composite interval mapping, a method that strips away the effects of QTLs detected initially in one or the other RI set, also enabled us to improve the strength of linkage of Nncl to Tstap91A. This bootstrap procedure may be particularly effective for mapping traits already known to differ substantially among the numerous inbred strains from which RIs already have been generated.

\section{Candidate genes}

Nnc1 maps between Hoxb and Krt1 (Watkins-Chow et al., 1996). This region contains three strong candidates for Nnc1: Rara, Thra, and Erbb2. All three genes encode receptors known to be expressed in retina early in development. It is also known that 
Figure 4. Prominent differences in the thickness of inner nuclear layers $(I N L)$ and outer nuclear layers $(O N L)$ between mice. These cross-sections of the midventral retina are taken at the same magnification (contrast-enhanced differential interference contrast optics). $A, \mathrm{BXD} 13$ case with a ganglion cell population of 51,600 (37-d-old male). Photoreceptor nuclei in the ONL of this retina were stacked $10-12$ cells deep, whereas cells in the INL were stacked $4-5$ cells deep. $B$, BXD32 case with a ganglion cell population of 85,600 (47-d-old male). Compared with the BXD13 retina, there are far fewer photoreceptors $(6-7$ cells deep), but more INL cells. Both strains have retinal surfaces areas that average 19 $\mathrm{mm}^{2}$ (Zhou and Williams, 1997). Scale bar, $30 \mu \mathrm{m}$.
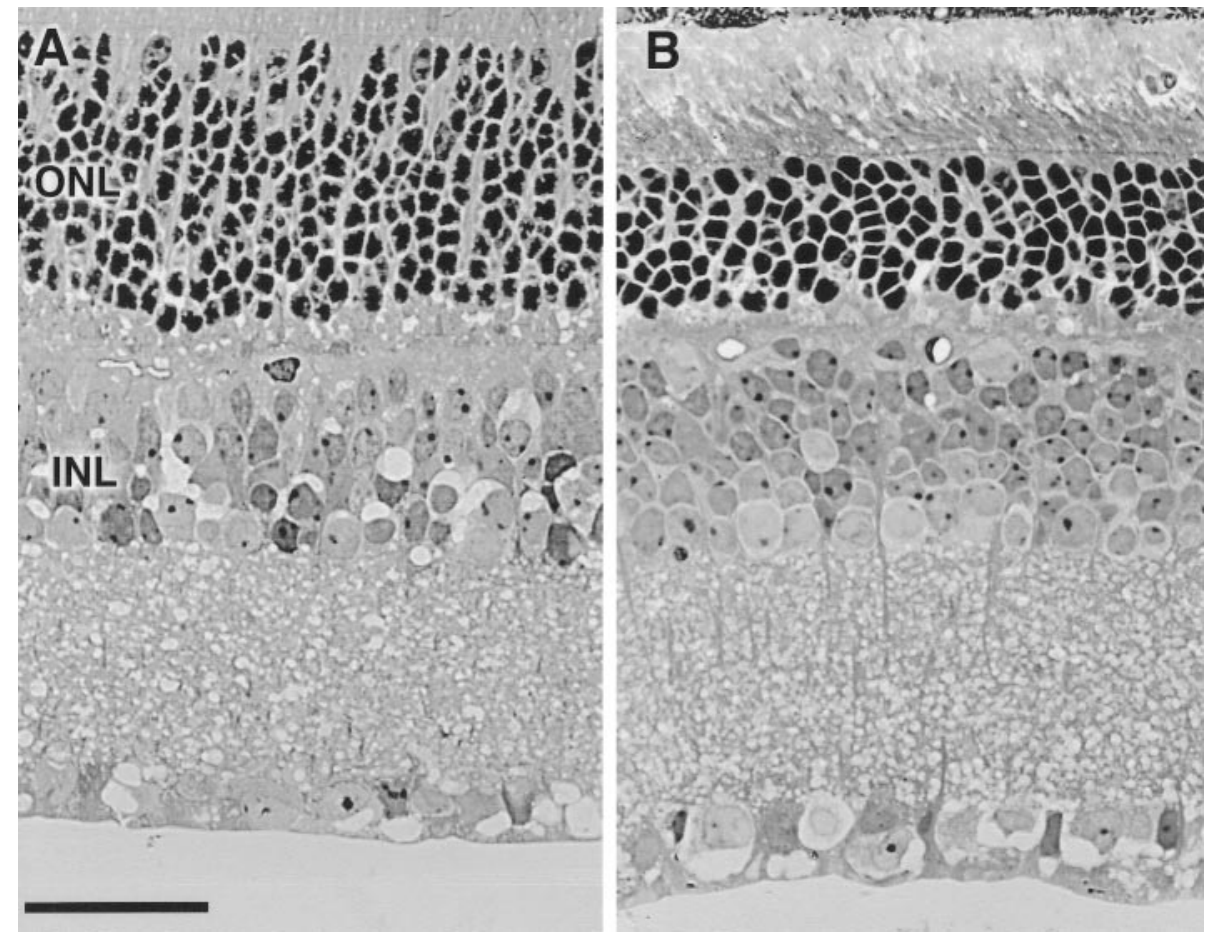

changing the concentrations of the ligands of these receptorsretinoic acid, thyroxine, and neuregulin-modulates the proliferation and survival of retinal cells (Beach and Jacobson, 1979; Hoskins and Grobstein, 1984; Hyatt et al., 1992; Stenkamp et al., 1993; Kelley et al., 1994, 1995; Bermingham-McDonogh et al., 1996; Hyatt et al., 1996). For example, an increase in thyroxine triggers the production of new retinal ganglion cells that specifically have uncrossed projections in Xenopus (Hoskins, 1985). The addition of exogenous retinoic acid increases rod production at the expense of amacrine cells (Kelley et al., 1994). Finally, neuregulin, a ligand that activates the erbB2 tyrosine kinase receptor (Meyer and Birchmeier, 1994), promotes ganglion cell survival in culture (Bermingham-McDonogh et al., 1996).

It is known that the loss of the $\alpha-1$ isoform of the retinoic acid receptor has minimal, if any, effect on eye or retina (Lufkin et al., 1993). But it is possible that mutant and null alleles at this gene have subtle quantitative effects, a possibility that we are now testing by counting ganglion cells in these knockout mice (R. W. Williams, R. C. Strom, G. Zhou, and V. Giguere, unpublished observations). The fact that many null mutants are viable and apparently normal has led to the idea that key developmental mechanisms are often controlled by products of several closely related genes. Some of the apparently redundant genes may function primarily as QTLs and maintain a reservoir of allelic and phenotypic variants.

\section{Time of gene action}

We have counted ganglion cells in high and low strains at birth, before the onset of naturally occurring cell death. Our results suggest that strain differences are already prominent at birth (Strom et al., 1995). By isolating the two alleles of $\mathrm{Nncl}$ on an otherwise isogenic background (congenic strains), we will be able to establish with more confidence whether Nncl modulates ganglion cell production or ganglion cell death.

\section{Genes known to affect the ganglion cell population}

A growing number of loci are known to influence numbers and ratios of retinal cell types when mutated, knocked out, or overexpressed. The list includes pearl (Williams et al., 1990), Brn3b (Erkman et al., 1996; Gan et al., 1996), Pax6 (Grindley et al., 1995), Mitf (Packer, 1967; Steingrimsson et al., 1994), Chx10 (Burmeister et al., 1996), Hes1 (Tomita et al., 1996), Bst (Rice et al., 1995b, 1997), Notch1 (Austin et al., 1995), Ccnd1 (Sicinski et and Weinberg, 1995), Bdnf (Johnson et al., 1986), Fgf (Cepko and Guillemot, 1992), Ngf (Ribacchi et al., 1994), and Bcl2 (Martinou et al., 1994; Bonfanti et al., 1996; Burne et al., 1996). The loss of $B r n 3 b$, for example, reduces ganglion cell numbers by $60-70 \%$. In contrast, overexpression of $B c l 2$ attenuates normal cell death, allowing twice the normal number of ganglion cells to survive. It is possible that normal alleles at these loci have more subtle effects and could account for some of the normal genetic variance not generated by alleles at $\mathrm{Nnc1}$.

\section{Genetics of natural variation}

The remarkable speed of brain evolution in response to shifts in selective pressure (Armstrong, 1983; Williams et al., 1993; Finlay and Darlington, 1995) is dependent on allelic variants at loci that control the size of neuron populations by proliferation and cell death. The fourfold increase in the size of the cerebellar cortex (Llinás and Walton, 1990) that has occurred over the past several million years in the lineage leading to modern humans was probably brought about by gene modifications that have increased proliferation in select groups of rhombencephalic progenitor cells. The reduction in neuron number in the cat's retina and dorsal lateral geniculate nucleus over a period of less than 20,000 years was probably brought about by changes in the severity of natural cell death (Williams et al., 1993). We anticipate that rapid progress in mapping QTLs with prominent effects on CNS traits will lead to a better understanding of the sources of natural 
variation in CNS structure and function and, ultimately, will lead to a deeper understanding of the genetic basis of brain evolution.

\section{REFERENCES}

Armstrong E (1983) Relative brain size and metabolism in mammals. Science 220:1302-1304.

Austin CP, Feldman DE, Ida JA, Cepko CL (1995) Vertebrate retinal ganglion cells are selected from competent progenitors by the action of Notch. Development 121:3637-3650.

Bailey DW (1981) Recombinant inbred strains and bilineal congenic strains. In: The mouse in biomedical research. Vol 1, pp 223-239. New York: Academic.

Beach DH, Jacobson M (1979) Influence of thyroxine on cell proliferation in the retina of the clawed frog at different ages. J Comp Neurol 183:615-624.

Belknap JK, Crabbe JC, Plomin R, McClearn GE, Sampson KE, O’Toole LA, Gora-Maslak G (1992) Single-locus control of saccharin intake in $\mathrm{BXD} / \mathrm{Ty}$ recombinant inbred (RI) mice: some methodological implications for RI strain analysis. Behav Genet 22:81-100.

Belknap JK, Mitchell SR, O’Toole LA, Helms ML, Crabbe JC (1996) Type I and type II error rates for quantitative trait loci (QTL) mapping studies using recombinant inbred mouse strains. Behav Genet 26:149-160.

Bermingham-McDonogh O, McCabe KL, Reh TA (1996) Effects of GGF/neuregulins on neuronal survival and neurite outgrowth correlate with erbB2/neu expression in developing rat retina. Development 122:1427-1438.

Bonfanti L, Stretto E, Chierzi S, Cenni MC, Liu XH, Martinou JC, Maffei L, Rabacci SA (1996) Protection of retinal ganglion cells from natural and axotomy-induced cell death in neonatal transgenic mice overexpressing $b c l-2$. J Neurosci 16:4186-4194.

Buck KJ, Metten P, Belknap JK, Crabbe JC (1997) Quantitative trait loci involved in genetic predisposition to acute alcohol withdrawal in mice. J Neurosci 17:3946-3955.

Burmeister M, Novak J, Liang MY, Basu S, Ploder L, Hawes NL, Vidgen D, Hoover F, Goldman D (1996) Ocular retardation mouse caused by Chx10 homeobox null allele: impaired retinal progenitor proliferation and bipolar cell differentiation. Nat Genet 12:376-384.

Burne JF, Staple JK, Raff MC (1996) Glial cells are increased proportionally in transgenic optic nerves with increased numbers of axons. J Neurosci 16:2064-2073.

Cepko CL, Guillemot F (1992) Retinal fate and ganglion cell differentiation are potentiated by acidic FGF in an in vitro assay of early retinal development. Development 114:743-754.

Churchill GA, Doerge RW (1994) Empirical threshold values for quantitative trait mapping. Genetics 138:963-971.

Curcio CA, Sloan Jr KA, Packer O, Hendrickson AE, Kalina RE (1987) Distribution of cones in human and monkey retina: individual variability and radial asymmetry. Science 236:576-582.

Dains K, Hitzeman B, Hitzeman R (1996) Genetics, neurolepticresponse and the organization of cholinergic neurons in the mouse striatum. J Pharmacol Exp Ther 279:1430-1438.

Erkman L, McEvilly RJ, Luo L, Ryan AK, Hooshmand F, O'Connell SM, Keithley EM, Rapaport DH, Ryan AF, Rosenfeld MG (1996) Role of transcription factors Brn-3.1 and Brn-3.2 in auditory and visual system development. Nature 381:603-606.

Finlay BL, Darlington RB (1995) Linked regularities in the development and evolution of mammalian brains. Science 268:1578-1584.

Gan L, Xiang M, Zhou L, Wagner DS, Klein WH, Nathans J (1996) Pou domain factor Brn-3b is required for the development of a large set of retinal ganglion cells. Proc Natl Acad Sci USA 93:3920-3925.

Gilissen E, Zilles K (1996) The calcarine sulcus as an estimate of the total volume of the human striate cortex: a morphometric study of reliability and intersubject variability. J Brain Res 37:57-66.

Gilissen E, Williams RW (1997) Genetic dissection and QTL analysis of forebrain, hindbrain, olfactory bulb, and cerebellum. Soc Neurosci Abstr 23:864.

Grindley J, Davidson D, Hill R (1995) The role of Pax-6 in eye and nasal development. Development 121:1433-1442.

Haley CS, Knott SA (1992) A simple regression method for mapping quantitative trait loci in line crosses using flanking markers. Heredity 69:315-324.

Haug H (1987) Brain sizes, surfaces, and neuronal sizes of the cortex cerebri: a stereological investigation of man and his variability and a comparison with some mammals (primates, whales, marsupials, insectivores, and one elephant). Am J Anat 180:126-142.

Hegmann JP, Possidente B (1981) Estimating genetic correlations from inbred strains. Behav Genet 11:103-114.

Hoskins SG (1985) Control of the development of the ipsilateral retinothalamic projection in Xenopus laevis by thyroxine: results and speculation. J Neurobiol 17:203-229.

Hoskins SG, Grobstein P (1984) Induction of the ipsilateral retinothalamic projection in Xenopus laevis by thyroxine. Nature 307:730-733.

Hyatt GA, Schmitt EA, Marsh-Armstrong NR, Dowling JE (1992) Retinoic acid-induced duplication of the zebrafish retina. Proc Natl Acad Sci USA 89:8293-8297.

Hyatt GA, Schmitt EA, Marsh-Armstrong N, McCaffery P, Drager UC, Dowling JE (1996) Retinoic acid establishes ventral retinal characteristics. Development 121:195-204.

Jansen RC (1993) Interval mapping of multiple quantitative trait loci. Genetics 135:205-211.

Johnson JE, Barde YA, Schwab M, Thoenen M (1986) Brain-derived neurotrophin factor supports the survival of cultured rat retinal ganglion cells. J Neurosci 6:3031-3038.

Kanes S, Dains K, Cipp L, Gatley J, Hitzemann B, Rasmussen E, Sanderson S, Silverman M, Hitzemann R (1996) Mapping the genes for haloperidol-induced catalepsy. J Pharmacol Exp Ther 277:1016-1025.

Kelley MW, Turner JK, Reh TA (1994) Retinoic acid promotes differentiation of photoreceptors in vitro. Development 120:2091-2102.

Kelley MW, Turner JK, Reh TA (1995) Ligands of steroid/thyroid receptors induce cone photoreceptors in vertebrate retina. Development 121:3777-3785.

Lai C, Lyman RF, Long AD, Langley CH, Mackay TFC (1994) Naturally occurring variation in bristle number and DNA polymorphisms at the scabrous locus of Drosophila melanogaster. Science 266:1697-1702.

Lande R (1981) The minimum number of genes contributing to quantitative variation between and within populations. Genetics 99:541-553.

Lander ES, Schork NJ (1994) Genetic dissection of complex traits. Science 265:2037-2048.

Lander E, Kruglyak L (1995) Genetic dissection of complex traits: guidelines for interpreting and reporting linkage results. Nat Genet 11:241-247.

Llinás RR, Walton KD (1990) Cerebellum. In: Synaptic organization of the brain. 3rd ed. (Shepherd GM, ed), pp 214-245. New York: Oxford UP.

Lufkin T, Lohnes D, Mark M, Dierich A, Gorry P, Gaub MP, LeMeur M, Chambon P (1993) High postnatal lethality and testis degeneration in retinoic acid receptor a mutant mice. Proc Natl Acad Sci USA 90:7225-7229.

Lynch M, Walsh B (1998) Mapping and characterizing QTLs: inbred line crosses. In: Genetics and analysis of quantitative characters, pp 91-131. San Francisco: Sinauer, http://nitro.biosci.arizona.edu/zbook/volume_1/ chapter_5/vol1_15.html.

Mackay TFC (1995) The genetic basis of quantitative variation: numbers of sensory bristles in Drosophila melanogaster as a model system. Trends Genet 11:464-470.

Martinou JC, Dubois-Dauphin M, Staple JK, Rodriguez I, Frankowski H, Missotten M, Albertini P, Talabot D, Catsicas S, Pietra C, Huarte J (1994) Overexpression of $\mathrm{Bcl}-2$ in transgenic mice protects neurons from naturally occurring cell death and experimental ischemia. Neuron 13:1017-1030.

Meyer D, Birchmeier C (1994) Distinct isoforms of neuregulin are expressed in mesenchymal and neuronal cells during mouse development. Proc Natl Acad Sci USA 91:1064-1068.

Packer SO (1967) The eye and skeletal effects of two mutant alleles at the microphthalmia locus of Mus musculus. J Exp Zool 1:21-45.

Plomin R, McClearn GE, Gora-Maslak G, Neiderhiser JM (1991) Use of recombinant inbred strains to detect quantitative trait loci associated with behavior. Behav Genet 21:99-116.

Ribacchi SA, Ensini M, Bonfanti L, Bravina A, Maffei L (1994) Nerve growth factor reduces apoptosis of axotomized retinal ganglion cells in the neonatal rat. Neuroscience 63:969-973.

Rice DS, Williams RW, Goldowitz D (1995a) Genetic control of retinal projections in inbred strains of albino mice. J Comp Neurol 354:459-469.

Rice DS, Williams RW, Ward-Bailey P, Johnson KR, Harris BS, Davisson MT, Goldowitz D (1995b) Mapping the Bst mutation on mouse chromosome 16: a model for human optic atrophy. Mamm Genome 6:546-548. 
Rice DS, Tang Q, Williams RW, Harris BS, Davisson MT, Goldowitz D (1997) Decreased retinal ganglion cell number and misdirected axon growth associated with fissure defects in Bst/+ mutant mice. Invest Ophthalmol Vis Sci 38:2112-2123.

Sicinski P, Weinberg R (1995) Cyclin D1 provides a link between development and oncogenesis in the retina and breast. Cell 82:621-630.

Steingrimsson E, Nii A, Fisher DE, Ferre-D'Amare AR, McCormick RJ, Russell LB, Burley SK, Ward JM, Jenkins NA, Copeland NG (1994) Molecular basis of mouse microphthalmia $(\mathrm{mi})$ mutations helps explain their developmental and phenotypic consequences. Nat Genet 8:256-263.

Stenkamp DL, Gregory JK, Adler R (1993) Retinoid effects in purified cultures of chick embryo retina neurons and photoreceptors. Invest Ophthalmol Vis Sci 34:2425-2436.

Strom RC, Williams RW, Goldowitz D (1995) Developmental mechanisms responsible for strain differences in the retinal ganglion cell population. Soc Neurosci Abstr 21:1523.

Strom RC, Goldowitz D, Williams RW (1996) Mapping quantitative trait loci that control retinal ganglion cell number using F2 intercross progeny. Soc Neurosci Abstr 22:518.

Tanksley SD (1993) Mapping polygenes. Annu Rev Genet 27:205-233.

Taylor B (1978) Recombinant inbred strains: use in gene mapping. In: Origins of inbred mice (Morse HC, ed), pp 423-438. New York: Academic.

Taylor B (1989) Recombinant inbred strains. In: Genetic variant and strains of the laboratory mouse, ED 2 (Lyon MF, Searle AG, eds), pp 773-796. New York: Oxford UP.

Tinker NA, Mather DE (1995) Methods for QTL analysis with progeny replicated in multiple environments. J Quant Trait Analysis 1: at http://probe.nalusda.gov:8000/otherdocs/jqtl/index.html.

Tomita K, Ishibashi M, Nakahara K, Ang SL, Nakanishi S, Guillemot F, Kageyama R (1996) Mammalian hairy and enhancer of split homolog 1 regulates differentiation of retinal neurons and is essential for eye morphogenesis. Neuron 16:723-734.
Watkins-Chow D, Roller M, Newhous MM, Camper SA, Buchberg AM (1996) Mouse chromosome 11. Mamm Genome 6:S201-220.

Williams MA, Piñon LGP, Linden R, Pinto LH (1990) The Pearl mutation accelerates the schedule of natural cell death in the early postnatal retina. Exp Brain Res 82:393-400.

Williams RW, Herrup K (1988) The control of neuron number. Annu Rev Neurosci 11:423-453.

Williams RW, Cavada C, Reinoso-Suárez F (1993) Rapid evolution of the visual system: a cellular assay of the retina and dorsal lateral geniculate nucleus of the Spanish wildcat and the domestic cat. J Neurosci 13:208-228.

Williams RW, Strom RC, Rice DS, Goldowitz D (1996a) Genetic and environmental control of variation in retinal ganglion cell number in mice. J Neurosci 16:7193-7205.

Williams RW, Strom RC, Goldowitz D (1996b) Mapping quantitative trait loci that control normal variation in brain weight in the mouse. Soc Neurosci Abstr 22:519.

Williams RW, Goldowitz D, Strom RC (1997) Brain weight in relation to body weight, age and sex: a multiple regression analysis. Soc Neurosci Abstr 23:864.

Williams RW, Strom RC, Zhou G, Yan Z (1998) Genetic dissection of retinal development. Semin Cell Dev Biol, in press.

Zamenhof S, van Marthens E (1978) Neonatal and adult brain parameters in mice selected for adult brain weight. Dev Psychobiol 9:587-593.

Zeng ZB (1993) Theoretical basis of separation of multiple linked gene effects on mapping quantitative trait loci. Proc Natl Acad Sci USA 90:10972-10976.

Zeng ZB (1994) Precision mapping of quantitative trait loci. Genetics 136:1457-1468.

Zhou G, Williams RW (1997) Mapping genes that control variation in eye weight, retinal area, and retinal cell density. Soc Neurosci Abstr 23:864. 